\title{
O ESTÁGIO DE OBSERVAÇÃO E AS APRECIAÇÕES VALORATIVAS DOS ESTAGIÁRIOS
}

\section{Lilian Cristina Buzato Ritter}

Universidade Estadual de Maringá

\author{
Cláudia Valéria Doná Hila \\ Universidade Estadual de Maringá
}

\begin{abstract}
Resumo
O momento que antecede o estágio de observação é bastante significativo para a análise de apreciações valorativas dos estagiários, pois elas interferem na reflexão crítica dessa etapa de formação. Diante desse contexto, o objetivo deste artigo é estabelecer uma análise sobre as apreciações valorativas que os estagiários possuem antes da realização do estágio de observação de aulas de língua portuguesa. Para atendermos a esse objetivo, realizamos uma pesquisa ação em andamento, de abordagem qualitativa. O trabalho pauta-se, sobretudo, na perspectiva da Análise Dialógica do Discurso e da concepção dialógica da linguagem (BAKHTIN/VOLOSHINOV, 1988; ACOSTA-PEREIRA; RODRIGUES, 2010) e está inserido em um projeto de pesquisa em andamento "Letramento para o local de trabalho: práticas de linguagem na formação inicial", da Universidade Estadual de Maringá, que faz parte do grupo de pesquisa "Interação e escrita" (UEMCNPq) (www.escrita.uem.br).
\end{abstract}

Palavras-chave: Estágio de Observação; Apreciações Valorativas; Dialogismo. 


\title{
PRACTICUM OBSERVATION STAGE AND ITS JUDGMENT BY PROSPECTIVE TEACHERS
}

\begin{abstract}
The moment preceding the practicum observation stage is very significant for the analysis of prospective teachers' judgment once it affects the critical reflection that is expected to occur at this stage of their education process. Thus, this study aims at analyzing the beliefs and values about the observation stage that prospective teachers of the Portuguese language bring with them before they start it. To respond to that aim we conducted an action research in progress, situated within the qualitative research perspective. The study is mainly grounded on The Dialogic Discourse Analysis and on the dialogic perspective of language (BAKHTIN/VOLOSHINOV, 1988; ACOSTAPEREIRA; RODRIGUES, 2010). It is both part of an ongoing research project called "Literacy for the workplace: language practices for pre-teaching education", being carried out at The State University of Maringá (UEM), and of the research group "Interação e escrita" (UEM-CNPq) (www.escrita.uem.br).
\end{abstract}

Keywords: Practicum Observation Stage; Judgment; Dialogism. 


\section{Introdução}

Este trabalho é fruto do projeto de pesquisa em andamento "Letramento para o local de trabalho: práticas de linguagem na formação inicial”, da Universidade Estadual de Maringá, inserido no grupo de pesquisa "Interação e escrita" (UEM-CNPq) (www.escrita.uem.br), no qual um grupo de professoras formadoras busca minimizar a distância ainda hoje existente entre aquilo que se faz nas universidades e aquilo que efetivamente se realiza nas escolas públicas, especialmente, no que diz respeito às práticas de linguagem desenvolvidas nos estágios supervisionados.

No caso específico do estágio de observação, esse hiato é ainda maior e mais problemático. Uma das razões para isso, constatada por anos de trabalho com o estágio de observação, é que os professores em formação, regra geral, entram nas escolas já com ideias preconcebidas em relação ao ensino-aprendizagem e tendem, na maioria das vezes, a culparem o professor em sala de aula pelos problemas didático-pedagógicos e disciplinares encontrados. Os professores em exercício, por sua vez, sentemse apenas avaliados e julgados, sem direito a qualquer contrapalavra, no sentido bakthiniano. Assim, instaura-se o seguinte contexto: professores em formação, de um lado, e os em exercício, de outro, agem como se fossem antagonistas em uma mesma situação. Exatamente por isso, encontrar escolas parceiras para o momento do estágio supervisionado tem sido cada vez mais difícil, principalmente, para o estágio de observação. Na maioria das vezes, a escola concede à universidade este espaço somente quando os estagiários realizam também o estágio de docência.

Um dos efeitos desta problemática revela-se no processo da produção escrita de diários de observação de aulas, os quais evidenciam a ausência de uma postura mais reflexiva sobre este momento da formação por parte dos estagiários. Consequentemente, podemos considerar que a realização do estágio pouco contribui para a formação crítica dos professorandos. Isso porque o diário de observação de aulas, muito comumente, propõe-se a cumprir a finalidade burocrática e operacional desta modalidade de estágio, anulando o contexto sócio-discursivo de tal prática de linguagem. Ao produ-

Olh@res, Guarulhos, v. 1, n1, p. 163-182, maio. 2013. 
zir gêneros discursivos como os diários de observação de aulas, no geral, o estagiário tende a repetir as palavras dos outros, ou alheias, sem transformálas em palavras próprias. De acordo com o pensamento bakhtiniano, "a 'palavra do outro' se transforma, dialogicamente, para tornar-se 'palavra pessoal-alheia' com a ajuda de outras 'palavras do outro', e depois, palavra pessoal (com, poder-se-ia dizer, a perda das aspas)" (BAKHTIN, 2003, p. 405-406). Transformar a palavra do outro em palavra minha envolve a participação dos estagiários, professores em exercício e professores formadores em atividades interativas mediadas pelo outro e pelas ferramentas de ensino, voltadas ao letramento, utilizadas nos estágios supervisionados.

Além da importância desse “outro" para a construção de uma responsividade mais ativa do estagiário, no momento da observação de aulas, as ferramentas utilizadas pelos professores formadores também podem (ou não) promover a reflexão crítica desses futuros professores. Essas ferramentas, além de auxiliarem o futuro professor a ter um olhar mais crítico sobre os elementos da aula, sejam eles materiais, discursivos, gestuais ou linguajeiros, devem promover o letramento do estagiário para o seu local de trabalho. O desenvolvimento de tal processo vai além da apropriação dos conhecimentos teóricos voltados para o ensino, abrangendo também "conhecimentos sobre as condições específicas de trabalho, as capacidades e interesses da turma, a disponibilidade de materiais e o acesso que a comunidade tem a eles" (KLEIMAN, 2008, p. 512).

Nesse sentido, voltamos nosso olhar ao gênero diário de observação, pois essa é a principal ferramenta utilizada no estágio de observação. Todavia, como está hoje configurada, ela apenas serve para avaliar o estagiário, sem dar efetivamente voz a esse estagiário e sem estabelecer qualquer interação com a escola. Entendemos que nós, professoras formadoras, assumindo a posição defendida por Kleiman (2007) de agentes de letramento, devemos procurar caminhos mais favoráveis para o desenvolvimento de atitudes mais críticas, por parte de nossos estagiários, em relação às suas experiências de estágio.

Olh@res, Guarulhos, v. 1, n1, p. 162-182, maio 2013. 
É exatamente esse contexto que nos motivou a realizar uma pesquisa, no intuito de investigarmos sobre como esse gênero, o diário de observação de aulas, amplamente utilizado nos cursos de licenciatura em Letras, pode realmente servir ao estagiário como uma ferramenta de ressignificação de sua futura prática profissional e não somente como um exercício de escrita obrigatório, apenas para comprovar as observações de aulas.

Dentro da perspectiva da Análise Dialógica do Discurso e da concepção dialógica da linguagem (BAKHTIN/VOLOSHINOV, 1988; ACOSTAPEREIRA; RODRIGUES, 2010), entendemos a situação social do estágio de observação como um evento discursivo único, porque é produzido uma única vez em determinada situação de interação, e também dialógico, visto que todo enunciado é uma resposta ao que já foi dito e espera uma nova resposta, em outras palavras, uma reação ativa por parte do interlocutor. Dessa forma, todo enunciado pressupõe os enunciados que o antecederam e todos os que o sucederão, porque não existe enunciado isolado, fora de um contexto de produção. Nas palavras de Bakhtin (2003, p.298), "a obra é um elo da cadeia da comunicação verbal", e, conforme essa afirmação, à luz do dialogismo, a linguagem pode ser considerada uma reação-resposta a um jádito em uma determinada situação de interação verbal, que manifesta a tensão entre as relações do locutor com os enunciados do outro. O outro não é entendido somente como o interlocutor físico, mas, principalmente, como as posições sociais assumidas por ele a partir de discursos diversos que permeiam a sociedade. Essas outras vozes discursivas constituem o discurso de forma heterogênea e apresentam-se em diferentes níveis no enunciado, instaurando o princípio da alteridade.

Podemos depreender dessas premissas que, para o Círculo bakhtiniano, as relações dialógicas engendram a produção de qualquer dizer, traduzindo, de certo modo, uma tensão nessa produção discursiva. Tomando as palavras de Bakhtin/Voloshinov (1988) acerca da dialogicidade interna do discurso e suas implicações quanto ao que já foi dito e à resposta antecipada, destacamos a assertiva: “[...] Ao se constituir na atmosfera do ‘já-dito', o discurso é orientado ao mesmo tempo para o discurso-resposta que ainda não foi dito, porém, que

Olh@res, Guarulhos, v. 1, n1, p. 163-182, maio. 2013. 
foi solicitado a surgir e que já era esperado. Assim é todo diálogo vivo" (BAKHTIN/VOLOSHINOV, 1988, p. 89).

Por causa desse viés dialógico, não é possível pensarmos em uma ressignificação do diário de observação, sem, anteriormente, compreendermos efetivamente o seu contexto de produção. Nesse sentido, os elementos sócio-históricos da situação enunciativa, no caso, o estágio de observação, determinam as condições reais dessa enunciação, fazendo-nos privilegiar, sobretudo, a vontade enunciativa do produtor do discurso que constrói seu texto, de acordo com a finalidade e a apreciação valorativa que faz sobre o(s) interlocutor(es) e o(s) tema(s).

Nessa perspectiva, para a produção deste artigo, focalizamos apenas um dos elementos dessa situação enunciativa: os professores em formação e suas apreciações valorativas a respeito do estágio de observação, antes de iniciarem esse processo. Portanto, o objetivo deste trabalho é estabelecer uma análise sobre as apreciações valorativas que os estagiários possuem antes da realização do estágio de observação de aulas de língua portuguesa. Para dar conta desse objetivo, dividimos o artigo em mais quatro seções, além desta introdução. $\mathrm{Na}$ seção a seguir, discutimos brevemente a fundamentação teórica que trata do contexto de produção, na perspectiva da Análise Dialógica do Discurso. Na sequência, apresentamos a metodologia do trabalho, descrevendo o instrumento questionário utilizado para sondagem das apreciações valorativas dos estagiários. Posteriormente, trazemos a análise dos dados, e, na última seção, apresentamos algumas considerações finais.

\section{O contexto de produção: breves reflexões epistemológicas}

As ideias fundadoras do Círculo de Bakhtin, especialmente, as presentes em Marxismo e filosofia da linguagem, ao criticarem as duas principais teorias linguísticas em curso no seu tempo, a do objetivismo abstrato e a do subjetivismo individualista, construíram a base de uma epistemologia filosófica da linguagem com a noção de enunciado concreto. Nesse âmbito,

Olh@ res, Guarulhos, v. 1, n1, p. 162-182, maio 2013. 
as ideias bakhtinianas invertem valores da linguagem e da língua cristalizados até aquele momento, argumentando que a língua é um signo ideológico:

\begin{abstract}
A verdadeira substância da língua não é constituída por um sistema abstrato de formas linguísticas, nem pela enunciação monológica isolada, nem pelo ato psicofisiológico de sua produção, mas pelo fenômeno social da interação verbal, realizada através da enunciação ou das enunciações. A interação verbal constitui assim a realidade fundamental da língua (BAKHTIN/ VOLOSHINOV, 1988, p. 123).
\end{abstract}

Dessa forma, observamos a importância das noções enunciado/enunciação na concepção de linguagem que rege o pensamento bakhtiniano porque a linguagem é concebida de um ponto de vista histórico, cultural e social, que inclui, para efeito de compreensão e análise, a comunicação efetiva e os sujeitos e os discursos envolvidos (BRAIT; MELO, 2005). Assim, a linguagem não representa meramente a realidade, mas cria no mundo estados de coisas novas. Passa a ser compreendida pela sua natureza sóciohistórica, sua ação interativa, uma vez que toda enunciação é uma resposta a alguém e a alguma coisa, e por isso "[...] Toda inscrição prolonga aquelas que a precederam, trava uma polêmica com elas, conta com as reações ativas da compreensão, antecipa-as" (BAKHTIN/VOLOSHINOV, 1988, p. 98).

Essa perspectiva enfatiza o caráter dialógico de toda enunciação. Ou seja, conforme já ressaltado, a situação de produção e os participantes dão forma à enunciação. De acordo com a visão bakhtiniana, "a situação social mais imediata e o meio social mais amplo determinam completamente e, por assim dizer, a partir do próprio interior, a estrutura da enunciação" (BAKHTIN/VOLOSHINOV, 1988, p. 113). Como contexto mais imediato pode-se inferir o meio social do micromundo (por exemplo, a família, a cidade, ...) e o contexto social mais amplo como o sócio-histórico (por exemplo, as relações socioeconômicas, culturais de uma sociedade, ...). Esses contextos não se encontram justapostos, como se fossem independentes e indiferentes uns aos outros, pelo contrário, encontram-se em uma situação de interação e de conflito ininterrupto.

Olh@res, Guarulhos, v. 1, n1, p. 163-182, maio. 2013. 
Para ampliarmos nosso entendimento a respeito da questão do contexto social na obra bakthiniana, retomamos Bakhtin/Voloshinov (1988, p. 1617) sobre a natureza ideológica do signo:

Todo signo é ideológico (...) O signo e a situação social estão indissoluvelmente ligados (...) A palavra é o signo ideológico por excelência; ela registra as menores variações da vida social. Para ele, a palavra veicula, de maneira privilegiada, a ideologia; a ideologia é uma superestrutura, as transformações sociais de base refletem-se na ideologia.

Sendo o signo ideológico, ele refrata por meio da palavra a ideologia da vida social. Há, portanto, uma relação dialética entre a palavra e a situação social, que entendemos como o contexto. Da mesma forma, todo enunciado/texto/gênero, materializado numa dada situação de interação, carrega as marcas e as influências do próprio contexto, com suas marcas ideológicas próprias. Nesse sentido, os autores evidenciam a dimensão ideológica da linguagem, bem como o fato de ela refratar as relações entre a infraestrutura de produção e a estrutura sociopolítica: "As relações de produção e a estrutura sociopolítica que delas diretamente deriva determinam todos os contatos verbais possíveis entre os indivíduos, todas as formas e os meios de comunicação verbal: no trabalho, na vida política, na criação ideológica" (BAKHTIN/VOLOSHINOV, 1988, p. 42).

Além dos participantes diretos da interação que se inserem no contexto social mais imediato, outra categoria do contexto de produção, de origem bakthiniana, é o intuito, o querer dizer do locutor (BAKHTIN, 2003). Esse querer dizer (ou finalidade da interação) se realiza na escolha de um gênero e é determinado tanto pela especificidade de uma dada esfera de comunicação (entendida como campos ideológicos, como a esfera da ciência, da religião, da educação, etc.) como pelas escolhas temáticas realizadas pelos parceiros da interação, a partir de suas apreciações valorativas.

Essa situação específica de produção e recepção de um enunciado envolve um outro conceito bakhtiniano: o de cronotopo. Para Bakhtin (2003), cada gênero discursivo está instaurado em uma determinada situação espacial e temporal que é única e não se repete (contexto sócio-histórico, esfera, suporte material), o que o leva a afirmar que "qualquer intervenção na esfera

Olh@res, Guarulhos, v. 1, n1, p. 162-182, maio 2013. 
dos significados só se realiza através da porta do cronotopo" (BAKHTIN, 2003, p.362). Do ponto de vista de sua historicidade, os enunciados, tais como os diários de observação, são dialógicos, na medida em que, sendo unidades concretas de comunicação, estabelecem ligações com outros enunciados já-ditos ou pré-figurados (ACOSTA-PEREIRA; RODRIGUES, 2010).

Também o tratamento exaustivo do objeto de sentido - o conteúdo temático, é parte constitutiva do enunciado. Bakhtin (2003) explica que o tema está circunscrito dentro dos limites do intuito definido pelo autor/locutor. Nesse sentido, cada gênero carrega consigo um conjunto de temas dizíveis ou permitidos para uma dada situação enunciativa. Por exemplo, o gênero cartão de aniversário traz como temas: felicitações, congratulações, não podendo, por exemplo, trazer temas como pêsames, reclamações, dentre outros.

Podemos esquematizar todas essas relações dialógicas entre os parâmetros da situação de produção dos enunciados (aqui também denominada de contexto de produção), assim como alguns autores já o fizeram (ROJO, 2005; HILA, 2011; RITTER, 2012), da seguinte forma:

\section{ESFERAS COMUNICATIVAS}

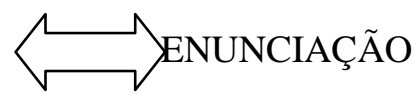

(de natureza social, histórica, ação interativa)<smiles>C1CCCCCC1</smiles>

\section{ENUNCIADO CONCRETO}

(sempre em diálogo com outros enunciados)<smiles>C1CCCCCC1</smiles>

- LOCUTOR e INTERLOCUTOR (os parceiros da enunciação e suas apreciações valorativas sobre o tema e a parceria; seus papéis sociais; suas relações hierárquicas e interpessoais);

- TRATAMENTO DADO AO TEMA (O QUE DIZER)

- VONTADE ENUNCIATIVA/FINALIDADE (QUERER DIZER)

- GÊNEROS DO DISCURSO (COMO DIZER)

Quadro 1. Elementos do contexto de produção na perspectiva da ADD. 
A seguir, engajamo-nos na análise de um dos aspectos do contexto de produção do gênero diário de observação, privilegiando, neste momento, conforme já adiantamos, apenas os estagiários e suas apreciações valorativas acerca do estágio de observação, antes de sua realização nas escolas.

\section{Metodologia}

No caso de pesquisas voltadas à análise de gêneros do discurso, conforme postulados de Bakhtin/Voloshinov (1988), essa postura dialógica diante do objeto discursivo segue uma ordem metodológica de análise que prioriza os aspectos sócio-históricos da enunciação. Rojo (2005, p. 199), ao explicar a ordem metodológica para o estudo da língua na abordagem sociológica bakhtiniana, defende que “(...) aqueles que adotam a perspectiva dos gêneros discursivos partirão sempre de uma análise em detalhe dos aspectos sócio-históricos da situação enunciativa, (...)". Em vista disso, podemos compreender que para o desenvolvimento de qualquer análise envolvendo gêneros discursivos, é imprescindível a análise das condições de produção do enunciado. Em função disso, o início de nossa investigação foi delimitado pelo reconhecimento e compreensão da orientação valorativa dos estagiários.

Portanto, para identificarmos e entendermos as apreciações valorativas dos estagiários que antecedem o estágio de observação de aulas de língua portuguesa, elaboramos um breve questionário composto por quatro questões abertas, aplicado a quinze estagiários do $3^{\circ}$ ano do curso de Letras Habilitação Dupla em Português-Inglês (período noturno) e de Letras Habilitação Única Português (período matutino). O questionário foi aplicado no início da disciplina Estágio Supervisionado II, ministrada no segundo semestre do ano letivo de 2012. Dessa maneira, os professorandos da pesquisa não haviam realizado observações em sala de aula durante a graduação. Na sequência, apresentamos as questões do referido questionário: 


\section{Por que você resolveu fazer o curso de Letras?}

2. Você deseja ser professor? Justifique.

3. Qual sua expectativa em relação às observações de aulas de professores em exercício?

4. A partir do seu conhecimento de mundo, que fatores você acredita poderem interferir no andamento de uma boa aula?

Para analisar os dados seguimos uma abordagem qualitativa para interpretar os dados. Assim, a análise dos dados consistiu em identificar, nos questionários aplicados, respostas que revelassem as apreciações valorativas dos estagiários acerca do momento de formação que estavam prestes a iniciarem, ou seja, o estágio de observação. Ressaltamos que as questões foram elaboradas com a finalidade de levantarmos categorias que nos auxiliassem a identificar e analisar essas apreciações valorativas dos estagiários.

As questões 1 e 2 têm a finalidade de verificarmos as orientações valorativas dos professorandos sobre alguns aspectos do contexto social mais amplo em que os estagiários estão inseridos: o papel da graduação em Letras e as possíveis relações dessa formação acadêmica com a prática profissional futura. Assumimos o papel social de professoras formadoras, e, nessa condição social, temos de levar em consideração que, muitas vezes, nos cursos de licenciatura, nem sempre a formação acadêmica coincide com o campo de atuação profissional de nossos alunos.

A questão 3 trata de modo mais específico da orientação valorativa dos estagiários acerca da prática de observação de aulas e de seu papel durante o referido estágio. Por fim, a questão 4 busca as significações dos estagiários a respeito do evento discursivo a ser observado, no caso, a aula.

\section{Análise dos dados}

Para efeitos didáticos, dividimos essa seção, de acordo com os temas inseridos na ferramenta questionário. E1, E2, E3... indicam os quinze professorandos envolvidos.

Olh@res, Guarulhos, v. 1, n1, p. 163-182, maio. 2013. 
Razões de escolher o curso de Letras

\begin{tabular}{|c|c|}
\hline Temáticas & $\begin{array}{l}\text { Exemplificações - excertos das respostas } \\
\text { dos estagiários }\end{array}$ \\
\hline Identificação com áreas afins ao curso & $\begin{array}{l}\text { E1: "acho o curso uma ótima oportunidade } \\
\text { para lidar com áreas que me identifico: } \\
\text { línguas e literatura" } \\
\text { E3: "por gostar de ler" } \\
\text { E8: "queria fazer jornalismo, não pude, mas } \\
\text { como gosto de leitura e escrita optei por } \\
\text { Letras" } \\
\text { E9: "tentei Direito várias vezes, como não } \\
\text { consegui optei por Letras" } \\
\text { E12: "sempre quis fazer Jornalismo, mas } \\
\text { nunca pude pagar o curso, daí fiz Letras" } \\
\text { E14: "nunca quis ser professor, ainda sonho } \\
\text { em fazer Direito" }\end{array}$ \\
\hline Desejo pessoal de ser professor & $\begin{array}{l}\text { E2: "sempre tive vontade de dar aulas de } \\
\text { gramática para o ensino médio e cursinho" } \\
\text { E4: "sempre quis lecionar" } \\
\text { E7: "desde o magistério achei que tinha tudo a } \\
\text { ver com ser professora" }\end{array}$ \\
\hline Influência de amigos & $\begin{array}{l}\text { E6: "por intermédio de uma amiga que iria } \\
\text { fazer vestibular para Letras e para } \\
\text { continuarmos juntas fazendo nossos trabalhos, } \\
\text { resolvi fazer também" }\end{array}$ \\
\hline Baixa concorrência do curso & $\begin{array}{l}\text { E7 e E5: "era o mais fácil de passar no } \\
\text { vestibular" } \\
\text { E10: "queria um curso de concorrência baixa, } \\
\text { e Letras me pareceu o mais viável" } \\
\text { E13: "um dos cursos menos concorridos e } \\
\text { como gostava de Português resolvi fazer" }\end{array}$ \\
\hline Falta de opção & $\begin{array}{l}\text { E11: "não sabia o que fazer, aí escolhi Letras } \\
\text { mesmo" } \\
\text { E15: "falta de opção, caí de paraquedas" }\end{array}$ \\
\hline
\end{tabular}

As respostas dadas chamam a atenção para o fato de que no grupo de quinze estagiários do $3^{\circ}$ ano do curso de Letras, apenas três manifestaram o desejo de terem optado conscientemente pelo curso. Retomando a ideia bakhtiniana de contexto social mais amplo, em nossa sociedade neoliberal, no geral, os cursos de licenciatura não possuem prestígio social e econômico, fator que se reflete na baixa concorrência desses cursos nas universidades públicas.

Olh@ res, Guarulhos, v. 1, n1, p. 162-182, maio 2013. 
Porém, nesse caso, parece haver um embate entre o esperado e o nãorealizado.

Se o desprestígio do curso não é motivo para alguns, para outros é a razão que os leva à escolha, na medida em que optar por aquilo que a maioria não deseja é um caminho mais seguro para se alcançar a esfera acadêmica. Exatamente por isso, alguns estagiários afirmaram que o desejo inicial era por cursos como Direito e Jornalismo, mas em função da concorrência nesses cursos ser maior, optaram por Letras. Portanto, observamos que as apreciações valorativas manifestadas pela maioria dos estagiários, reacentuam o desprestígio socioeconômico do curso de licenciatura em Letras.

\section{Razões para atuar profissionalmente como professor}

Dos quinze estagiários participantes, dez responderam afirmativamente à pergunta, revelando que querem ser professores. Três não justificaram e dois afirmaram não quererem ser professores, apenas "ter um curso superior" (E11). E14, por sua vez, afirmou que nunca quis ser professor.

Como a maioria respondeu afirmativamente, elencamos abaixo algumas das razões por eles apontadas:

\begin{tabular}{|l|l|}
\hline Temáticas & $\begin{array}{l}\text { Exemplificações- excertos das respostas dos } \\
\text { estagiários }\end{array}$ \\
\hline Paixão pela profissão & $\begin{array}{l}\text { E7: "agora, depois de muito tempo estudando, } \\
\text { passei a me apaixonar pela profissão" }\end{array}$ \\
\hline $\begin{array}{l}\text { Participação em projetos de pesquisa, de } \\
\text { docência. }\end{array}$ & $\begin{array}{l}\text { E8: "fiz meu primeiro PIC já trabalhando na } \\
\text { escola com textos literários, depois com a } \\
\text { minha participação no Pibid realmente percebi } \\
\text { que posso e quero ser professor" } \\
\text { E10: "comecei a pensar em ser professora } \\
\text { quando já no segundo ano participei de um } \\
\text { PIC envolvendo a Educação de Jovens e } \\
\text { Adultos, hoje tenho certeza de que estou no } \\
\text { lugar certo." } \\
\text { E12: "não pensava em ser professora, mas } \\
\text { agora participando de um PIC que envolve a } \\
\text { escrita no vestibular e aplicando os resultados } \\
\text { em sala de aula comecei a perceber que ser } \\
\text { professora não é mais uma opção para mim, é } \\
\text { o que escolhi para meu futuro" }\end{array}$ \\
\hline
\end{tabular}

Olh@res, Guarulhos, v. 1, n1, p. 163-182, maio. 2013. 


\begin{tabular}{|l|l|}
\hline Importância social da profissão & $\begin{array}{l}\text { E3: “apesar do descrédito que a profissão } \\
\text { carrega, creio que seja uma das poucas em } \\
\text { que é possível sentir-se fazendo algo útil para } \\
\text { alguém" } \\
\text { E4: "eu escolhi essa profissão porque acho } \\
\text { importante contribuir para a educação do } \\
\text { país" } \\
\text { E5: "lecionar é uma atividade muito } \\
\text { compensadora" posso } \\
\text { E9: "acredito que como professora posso } \\
\text { auxiliar meus alunos a tornaram-se } \\
\text { efetivamente cidadãos nesse país" }\end{array}$ \\
\hline Visão cristã da profissão & $\begin{array}{l}\text { E13: "quero ser professora para ajudar o } \\
\text { próximo mesmo, educar é uma missão" }\end{array}$ \\
\hline Visão preconceituosa do ensino público & $\begin{array}{l}\text { E6: "quero ser professor, mas de cursinhos ou } \\
\text { ensino superior, de escola pública nem } \\
\text { pensar". }\end{array}$ \\
\hline
\end{tabular}

As respostas acima apontam para apreciações valorativas bastante positivas, na medida em que estabelecem uma relação dialógica de assimilação do discurso atual que valoriza socialmente a figura do professor em nossa sociedade, como revelam as respostas de E3, E4, E5 e E9.

Outra apreciação positiva se dá com relação à própria vida acadêmica que impulsiona e ressignifica as posições de estagiários que, muitas vezes, não pensavam em atuarem profissionalmente como professores (E8, E10 e E11). Projetos de iniciação científica (PIC) e o recente 'Programa Institucional de Bolsas de Iniciação à Docência (Pibid) fazem parte de ações realizadas no contexto mais amplo e mais imediato, que levam os professorandos a estabelecerem uma orientação valorativa positiva do curso e da profissão de docente.

Ainda com relação ao contexto mais imediato, representado pela família, pela Igreja e outras instâncias sociais e culturais, por exemplo, destacamos a resposta de E13, que enxerga sua escolha como uma missão para ajudar os mais oprimidos. Na realidade, tem-se aqui revelada a natureza dialógica do signo (BAKHTIN/VOLOSHINOV, 1988), que não se dissocia do locutor e de seu dizer.

Olh@res, Guarulhos, v. 1, n1, p. 162-182, maio 2013. 
Expectativas em relação à observação de aulas de LP: objetivos da observação

\begin{tabular}{|c|c|}
\hline Temáticas & $\begin{array}{l}\text { Exemplificações- excertos das respostas dos } \\
\text { estagiários }\end{array}$ \\
\hline Aprender com o professor em exercício & $\begin{array}{l}\text { E1, E13 e E15: "boas, porque espero aprender } \\
\text { mais" } \\
\text { E7: "aprender com os erros e acertos do } \\
\text { professor" } \\
\text { E4: "aprender com o professor o que fazer e o } \\
\text { que não fazer em sala de aula." } \\
\text { E6: "aprender técnicas de ensino e de domínio } \\
\text { de comportamento" } \\
\text { E8: "tentar aprender mais sobre a prática" }\end{array}$ \\
\hline Aprender com o aluno & $\begin{array}{l}\text { E4: "com os alunos, espero aprender sobre o } \\
\text { que eles gostam ou não nas aulas" }\end{array}$ \\
\hline Analisar a aula & $\begin{array}{l}\text { E5: "boa oportunidade para, de um olhar de } \\
\text { fora, analisarmos o ambiente e andamento de } \\
\text { uma aula" } \\
\text { E12: "precisamos olhar aulas para entendê- } \\
\text { las, ver e analisar a prática é fundamental para } \\
\text { aprendermos" }\end{array}$ \\
\hline Servir como incentivo & $\begin{array}{l}\text { E2: "espero que as observações me } \\
\text { incentivem mais no meu desejo de dar aulas } \\
\text { para o ensino médio" }\end{array}$ \\
\hline Servir como experiência & $\begin{array}{l}\text { E9 e E11: "independente do que eu encontrar, } \\
\text { sei que o estágio vai me servir como } \\
\text { experiência para minha futura vida } \\
\text { profissional" }\end{array}$ \\
\hline Constatar as dificuldades & $\begin{array}{l}\text { E3: "constatar novamente, as dificuldades que } \\
\text { o professor enfrenta a todo instante" } \\
\text { E10: "já sabemos por outros colegas que não } \\
\text { vemos ver coisas boas, mas espero também } \\
\text { aprender com as dificuldades que verei" }\end{array}$ \\
\hline \multicolumn{2}{|c|}{$\begin{array}{l}\text { Podemos observar que as três primeiras temáticas revelam o lugar de } \\
\text { ancoragem ideológica que situa o discurso dos estagiários em relação à } \\
\text { observação de aulas: é um olhar fechado em si mesmo, no qual se busca } \\
\text { julgar as ações pedagógicas do professor em exercício em positivas e }\end{array}$} \\
\hline
\end{tabular}

Olh@res, Guarulhos, v. 1, n1, p. 163-182, maio. 2013. 
negativas. O professorando busca modelos positivos ou negativos de formação. Da mesma forma, quando se referem aos alunos, os índices sociais de valor também se constituem pelo modelo de aluno "satisfeito" (aquele que gostou das aulas) e "insatisfeito" (aquele que não gostou das aulas).

Nesse sentido, o papel do estagiário seria o de avaliar tanto a conduta do professor quanto a do aluno, e, neste caso, a observação funcionaria somente como uma avaliação das aulas, negligenciando as condições sóciohistóricas de tais ações produzidas em um determinado contexto educacional. Essas apreciações valorativas conferem à observação de aulas um status técnico e teórico. A prática de observação estaria a serviço de uma avaliação das ações do professor em exercício e do comportamento do aluno, feita de maneira homogênea e descontextualizada.

As três últimas respostas revelam o discurso ancorado na concepção de estágio como um cumprimento institucional, seja por reacentuações positivas, no caso, servindo de "incentivo" ou como "experiência profissional", seja por valoração negativa, validando somente as dificuldades do trabalho docente.

No geral, o papel social assumido pelos professorandos é o de estagiários expectadores na situação de observação de aulas, visto que se colocam de modo passivo nessa interação discursiva. Assim, como expectadores, eles esperam que os modelos de conduta profissional observados possam ser reproduzidos ou excluídos em sua formação profissional.

Fatores prejudiciais ao desenvolvimento de uma boa aula

No que diz respeito aos fatores prejudiciais ao desenvolvimento de uma boa aula, os estagiários estabelecem uma relação dialógica de assimilação do discurso já-dito em nossa sociedade, particularmente, em relação a discursos da esfera educacional, como podemos observar no quadro a seguir:

Olh@res, Guarulhos, v. 1, n1, p. 162-182, maio 2013. 


\begin{tabular}{|c|c|}
\hline Temáticas & $\begin{array}{l}\text { Exemplificações - excertos das respostas } \\
\text { dos estagiários }\end{array}$ \\
\hline Fatores relacionados aos alunos & $\begin{array}{l}\text { E2: "desnível de conhecimento, falta de } \\
\text { atenção" } \\
\text { E3 e E15: "conversas paralelas, falta de } \\
\text { educação" } \\
\text { E5: "indisciplina de alunos, conversa paralela } \\
\text { e falta de atenção" } \\
\text { E7: "hiperatividade dos alunos" } \\
\text { E8: "mau comportamento dos alunos" } \\
\text { E10: "falta de respeito dos alunos" }\end{array}$ \\
\hline Fatores relacionados ao professor & $\begin{array}{l}\text { E1: "aula muito parada, quando não se leva } \\
\text { em consideração o conhecimento de mundo } \\
\text { do aluno" } \\
\text { E4: "aula mal planejada" } \\
\text { E6: "textos descontextualizados, não permitir } \\
\text { que os alunos participem da aula com suas } \\
\text { opiniões" } \\
\text { E7: "stress do professor" } \\
\text { E13: "despreparo do professor tanto do } \\
\text { conhecimento como em relação ao uso das } \\
\text { tecnologias" } \\
\text { E14: "falta de atualização do professor" }\end{array}$ \\
\hline $\begin{array}{l}\text { Fatores } \\
\text { escolas }\end{array}$ & $\begin{array}{l}\text { E7: "estrutura física } \\
\text { superlotação da sala" }\end{array}$ \\
\hline Fatores relacionados à família & $\begin{array}{l}\text { E9 e E11: "falta de base familiar" } \\
\text { E12: "falta de engajamento da família" }\end{array}$ \\
\hline
\end{tabular}

A grande maioria dos estagiários responsabiliza alunos e professor em exercício pelas dificuldades em se desenvolver uma boa aula. As apreciações valorativas dos estagiários revelam, mais uma vez, a visão tecnicista e descontextualizada do objeto da observação, a aula. Consequentemente, a aula é abstraída de suas reais condições sóciohistóricas, invertendo-se, portanto, a ordem causa/consequência, uma vez que, por exemplo, a falta de atenção dos alunos, o despreparo do professor, correspondem somente a fatores relacionados aos atores sociais envolvidos

Olh@res, Guarulhos, v. 1, n1, p. 163-182, maio. 2013. 
diretamente nesse contexto de ensino-aprendizagem, considerando-os como os únicos responsáveis pelo "mal andamento" de uma aula.

Axiologicamente, a maioria dos estagiários demonstra assimilar já-ditos que permeiam nossa sociedade, no tocante às condutas docentes e discentes, como: "hoje, o aluno não reconhece mais a autoridade do professor em sala de aula"; "o aluno não tem limites"; "hoje, o professor não sabe mais o que e como ensinar". Já, nas duas últimas temáticas, são apontados fatores relacionados a razões mais profundas, da ordem do macrossocial, como família e infraestrutura das escolas públicas. Aqui, o horizonte valorativo ancora-se em questões de ordem político-governamental, assimilando dizeres muito presentes na esfera educacional, como: "a família precisa estar mais presente nas escolas"; "o governo deve investir mais na educação pública".

\section{Considerações finais}

O objetivo deste artigo é identificar e analisar as apreciações valorativas de estagiários, antes de iniciarem o estágio de observação em aulas de língua portuguesa. Sobre essas apreciações constatamos que:

- a observação de aulas é vista pelos estagiários como uma atividade avaliativa, na qual o professor em exercício e os alunos do ensino fundamental e médio representam modelos de condutas que podem ou não serem reproduzidos na formação inicial;

- o papel social assumido pelos estagiários é de um expectador que reproduz ou não modelos observados.

No papel social de professoras formadoras, podemos problematizar essas constatações a respeito das apreciações valorativas dos professorandos, com o intuito de oportunizar-lhes uma postura mais crítica durante o estágio de observação. Elas podem ser uma excelente fonte de discussão nos encontros de supervisão de estágio, pois nos indicam que a observação de aulas parece ser tratada nos cursos de formação como uma prática naturalizada, na qual não se exige questionamentos.

Olh@ res, Guarulhos, v. 1, n1, p. 162-182, maio 2013. 
Assim, com o intuito de "desnaturalizar" tal prática de formação, é que nos engajamos como formadoras, na medida em que sentimos a necessidade de reconstruirmos essa etapa do estágio do curso de licenciatura em Letras como um espaço para o cultivo de atitudes mais colaborativas e coletivas, investindo-se em posturas reflexivas acerca de nossas questões sóciohistóricas.

Olh@res, Guarulhos, v. 1, n1, p. 163-182, maio. 2013. 


\section{Referências Bibliográficas}

ACOSTA-PEREIRA, A.R.; RODRIGUES, R.H. Os gêneros do discurso sob perspectiva da Análise Dialógica de Discurso do Círculo de Bakhtin. Revista Letras, Santa Maria: UFSM, v.20,n.42,p.147-162,jan/jun,2010.

BAKHTIN, M.M. Estética da criação verbal. 4. ed. São Paulo: Martins Fontes, 2003.

BAKHTIN, M. M. ; VOLOSHINOV, V. N. Marxismo e filosofia da linguagem. 4. ed. São Paulo: Hucitec, 1988.

BRAIT, B.; MELO, R. Enunciado/enunciado concreto/enunciação. In: BRAIT, B. (Org.). Bakhtin: conceitos-chave. São Paulo: Contexto, 2005. p. 61-78.

HILA,C.V.D. Ferramentas curso de formação e sequência didática: contribuições para o processo de internalização no estágio de docência de língua portuguesa.Tese (Doutorado em Estudos da Linguagem). Londrina, UEL: 2011

KLEIMAN, A. Os estudos de letramento e a formação do professor de língua materna. Revista Linguagem em (Dis)curso, volume 8, número 3, set/dez, 2008, p.56-84. - Letramento e suas implicações para o ensino de língua materna. Revista Signo, Santa Cruz do Sul, v. 32, n. 53, p. 1-25, dez. 2007.

RITTER, L. C. B. Práticas de leitura/análise linguística com crônicas no ensino médio: proposta de elaboração didática. Tese (Doutorado em Estudos da Linguagem). Londrina, UEL: 2012.

ROJO, R. Gêneros do discurso e gêneros textuais: questões teóricas e aplicadas. In: MEURER, J. L; BONINI, A.; MOTTA-ROTH, D. (orgs). Gêneros: teorias, métodos, debates. São Paulo: Parábola, 2005, p. 184-293. 